Quality : Jurnal Kesehatan

Volume 14, Nomor 1 Tahun 2020

pISSN : 1978-4325, eISSN : 2655-2434, DOI: 10.36082/qjk.v14i1.98

\title{
IN-BRACE CORRECTION (IBC) TERHADAP TIPE DAN BESARAN KURVA PADA PASIEN ADOLESCENT IDIOPATHIC SKOLIOSIS (AIS)
}

\author{
Raden Achmad Candra Putra ${ }^{1}$, Fika Trifani ${ }^{1}$ \\ ${ }^{1}$ Jurusan Ortotik Prostetik, Politeknik Kesehatan Kemenkes Jakarta I, Indonesia
}

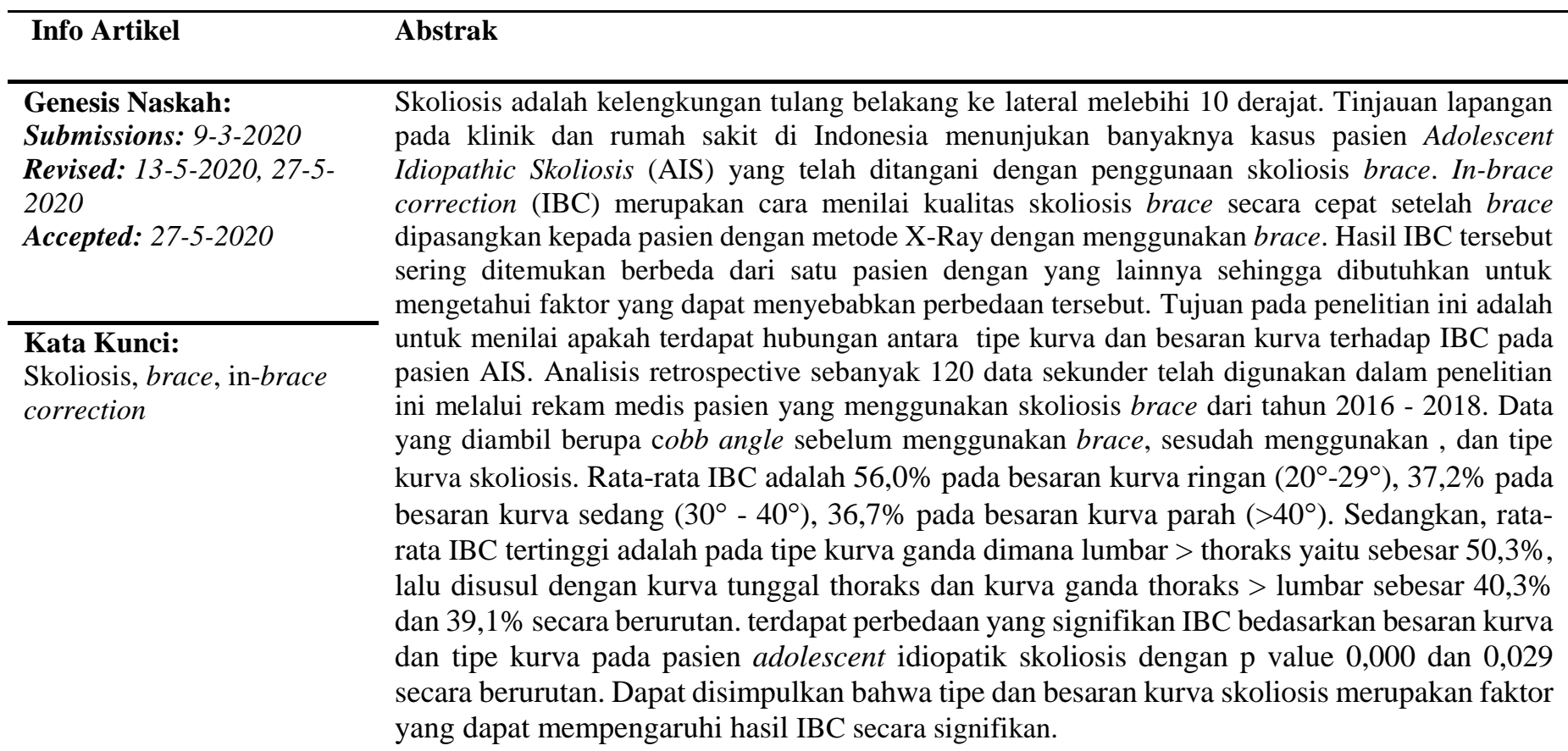

\section{IN-BRACE CORRECTION TO CURVE TYPE AND MAGNITUDE IN PATIENTS WITH ADOLESCENT IDIOPATHIC SKOLIOSIS (AIS)}

\section{Keywords:}

Skoliosis, brace, in-brace correction

\section{Abstract}

Scoliosis is a lateral curvature of the spine that exceeds 10 degrees. Many clinics and hospitals in Indonesia have many cases of Adolescent Idiopathic Scoliosis (AIS) patients who have been treated with the use of scoliosis brace. In-Brace Correction (IBC) is a way of assessing the quality of scoliosis brace quickly after the brace is fitted to patients in X-Ray method. However, the results of the IBC are often found differently from one patient to another so it is necessary to know the factors that can cause such differences. Therefore, the purpose of this study was to assess whether the curve type and magnitude influence on the IBC in AIS patients. Retrospective analysis with total of 120 secondary data has been used in this study from 2016 -2018. Cobb angle without the use of brace, In-Brace Cobb angle, and scoliosis curve type were recorded. The average of IBC was $56.0 \%$ at a mild curve $\left(20^{\circ}-29^{\circ}\right), 37.2 \%$ at medium curves $\left(30^{\circ}-40^{\circ}\right), 36.7 \%$ at severe curve magnitudes $(>40 \%$. Meanwhile, the average IBC were on a double curve type where lumbar > thoracic is $50.3 \%$, followed by a single thoracic curve and double curve, thoracic > lumbar amounting to $40.3 \%$ and $39.1 \%$ respectively. There is a significant difference in the IBC based on curves and
(C) Poltekkes Kemenkes Jakarta I

Jl. Wijaya Kusuma No. 47-48 Cilandak Jakarta Selatan, Indonesia email: jurnalquality@poltekkesjakarta1.ac.id
ISSN 2655-2434

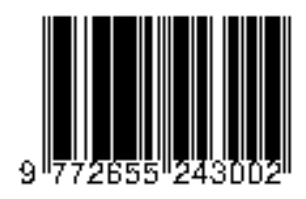


curve type in AIS patients with p-value 0.000 and 0.029 respectively. It can be concluded that the type and magnitude of scoliosis curve are the factors can affect the results of IBC significantly.

\section{Korespondensi Penulis:}

Raden Achmad Candra Putra

Jl. Wijaya Kusuma Raya no.48

Email: candra@jspo.ac.id 


\section{Pendahuluan}

Skoliosis adalah kelengkungan tulang belakang ke lateral yang melebihi 10 derajat menurut Scoliosis Research Society (SRS). Skoliosis merupakan kelainan tulang belakang yang menjadikan tulang belakang bengkok ke samping kiri atau kanan sehingga wujudnya merupakan bengkok benjolan yang dapat dilihat dengan jelas dari arah belakang. Penyakit ini juga sulit untuk dikenali kecuali setelah penderita meningkat menjadi dewasa

Sekitar $80 \%$ skoliosis didunia adalah idiopatik, Skoliosis idiopatik dengan kurva lebih dari 10 derajat dilaporkan dengan prevalensi 0,5-3 per 100 anak dan remaja. Prevalensi dilaporkan pada kurva lebih dari 30 derajat yaitu 1,5-3 per 1000 penduduk. Sekitar 4\% dari seluruh anak-anak yang berumur 10-14 tahun mengalami skoliosis, 40-60\% diantaranya ditemukan pada anak perempuan. Skoliosis terjadi kira-kira dua kali lebih umum pada anak perempuan daripada anak lelaki (Brian V. \& Joseph B., 2001; Konieczny, Senyurt, \& Krauspe, 2013).

Idiopatik skoliosis sering ditangani dengan pengobatan konservatif yaitu dengan bracing dan terapi fisik. Efektivitas penggunaan brace telah diperdebatkan selama bertahun-tahun. Terdapat beberapa penelitian yang dapat memberikan gambaran yang jelas tentang bagaimana brace mempengaruhi besarnya akhir kurva, laju perkembangan, atau reduksi dalam pengobatan bedah dibutuhkan setelah penggunaan brace (Maruyama, Grivas, \& Kaspiris, 2011; Stuart L. Weinstein, Dolan, Wright, \& Dobbs, 2013). Pengobatan konservatif merupakan upaya untuk mencegah perkembangan kurva Pembedahan telah digunakan untuk kurva yang besar atau kurva yang progresif saat ini

Penggunaan ortotik atau brace pada skoliosis ini bertujuan untuk mengontrol lekukan tulang belakang sampai menunggu pematangan tulang secara permanent. Penggunaan brace adalah upaya untuk memodifikasi bentuk mekanis dan mengkontrol perkembangan kurva pada lekukan tulang belakang dengan menerapkan titik-titik tekanan tertentu pada batang tubuh (Kuroki, 2018).

(C) Poltekkes Kemenkes Jakarta I

Jl. Wijaya Kusuma No. 47-48 Cilandak Jakarta Selatan, Indonesia email: jurnalquality@poltekkesjakarta1.ac.id
Bedasarkan pengamatan peneliti, bahwa diketahui banyaknya kasus pasien skoliosis di Indonesia yang ditangani dengan penggunaan skoliosis brace. Bedasarkan tinjauan lapangan, di beberapa klinik ortotik di Jakarta, terdapat 10-15 pelayanan skoliosis brace per bulannya.. Sehingga diperkirakan adanya pelayanan sebanyak 200 pasien sudah diberikan pelayanan skoliosis brace dari tahun 2014 - 2017. Dari pelayanan tersebut didapati adanya perbedaan In-brace correction (IBC) pada setiap pasien.

IBC merupakan metode dengan pemanfaatan radiograph yang sangat efektif untuk evaluasi koreksi yang dihasilkan brace secara cepat (Clin, Aubin, Sangole, Labelle, \& Parent, 2010; Landauer, Wimmer, \& Behensky, 2003). Standar IBC untuk pengkoreksian AIS telah dilakukan oleh untuk menyamakan persepsi jumlah koreksi pada skoliosis brace yang menyatakan bahwa skoliosis brace harus mencapai 50\% koreksi dari besaran kurva setelah pasien menggunakan skoliosis brace (Knott et al., 2013). Diketahui bahwa terdapat faktor yaitu tipe kurva dan besaran derajat yang dapat berpengaruh dalam pencapaian IBC (Katz \& Durrani, 2001; Lang et al., 2019) . Tujuan pada penelitian ini adalah untuk menilai apakah terdapat hubungan antara tipe kurva dan besaran kurva terhadap IBC pada pasien AIS.

\section{Metode}

Retrospektif analisis pada pasien dengan AIS yang mendapatkan penanganan brace pada klinik ortotik dari tanggal 1 Januari 2016 - 31 Maret 2018. Pemilihan subjek penelitian bedasarkan kriteria dari Scoliosis Research Society (SRS) (Negrini et al., 2018) untuk penelitan pada brace. Kriteria subjek meliputi Pasien dengan diagnosa awal AIS, umur $\geq 10$ tahun, besaran kurva utama lebih besar dari 20 derajat, Risser sign $0-2$ dan tercatat pada saat awal pembuatan brace, tidak ada riwayat penganan medik lain. data diambil dengan mencatat cobb angle sebelum dan sesudah menggunakan brace dengan perhitungan sbb:

$$
I B C(\%)=\frac{C A S B-C A D B}{C A S B} \times 100
$$

$\underline{\text { Keterangan }}$

CASB $\quad:$ Cobb Angle sebelum menggunakan Brace ISSN 2655-2434 
CADB : $\begin{aligned} & \text { Cobb Angle dengan menggunakan } \\ & \text { Brace }\end{aligned}$

Kemudian, hasil IBC akan dianalisis secara univariat dan bivariat untuk melihat hubungannya terhadap tipe dan besaran kurva skoliois dengan uji two-way ANOVA

\section{Hasil}

Besaran kurva skoliosis diukur dengan metode cobb angle. Tabel 1 menunjukan bahwa besaran kurva pada sampel penelitian ini yaitu sebanyak 50 orang $(41,7 \%)$ memiliki besaran kurva dengan tingkat sedang $\left(30^{\circ}-39^{\circ}\right), 45$ orang $(35,5 \%)$ dengan tingkat parah $\left(\geq 40^{\circ}\right)$, sedangkan terdapat 25 orang $(20,8 \%)$ yang memiliki besaran kurva dengan tingkat ringan $\left(20^{\circ}-29^{\circ}\right)$.

Tabel 1. Karakteristik Sampel

\begin{tabular}{lc}
\hline \multicolumn{1}{c}{ Variabel } & Subjects $(\mathbf{n}=\mathbf{1 2 0})$ \\
\hline IBC & $41 \pm 20,25(6-89)$ \\
Tipe Kurva & \\
Kurva S, L $>$ T & $39(32,5 \%)$ \\
Kurva S, T $>$ L & $29(24,2 \%)$ \\
$\quad$ Kurva T Tunggal & $52(43,3 \%)$ \\
Besaran Kurva $\left({ }^{\circ}\right)$ & \\
Ringan $(20-29)$ & $25(20,8 \%)$ \\
Sedang $(30-39)$ & $50(41,7 \%)$ \\
Parah $(\geq 40)$ & $45(37,5 \%)$ \\
\hline
\end{tabular}

Data ditampilkan dalam bentuk mean $\pm \mathrm{SD}(\min -\max )$ atau jumlah (\%).

Tipe kurva skoliosis pada pasien AIS dianalisis pad x-ray pasien ketika awal datang ke klinik. Tabel 1. menunjukan sebanyak 52 orang $(43,3 \%)$ memiliki kurva thoracic tunggal, 39 orang $(32,5 \%)$ memiliki kurva kurva ganda dimana Lumbar lebih besar daripada Thoracic, sendangkan tipe kurva terkecil yaitu tipe kurva ganda dimana Thoracic lebih besar daripada Lumbar sebanyak 29 orang $(24,2 \%)$. Rata-rata IBC yang dikoreksi dengan penggunaan brace adalah $41 \%$ (95\%CI: 37,33 - 44,65), median $40,65 \%$ dengan standar deviasi $20,25 \%$. IBC terkecil yaitu $6 \%$ dan terbesar $89 \%$.
Tabel 2 menunjukan Rata-rata IBC terhadap tipe kurva dan besaran kurva. Didapatkan rata-rata IBC tertinggi adalah pada tipe kurva ganda dimana lumbar > Thoracic yaitu sebesar 50,3\%, lalu disusul dengan kurva tunggal thoracic dan kurva ganda thoracic > lumbar sebesar 40,3\% dan 39,1\% secara berurutan. Sedangkan rata-rata IBC terhadap besaran kurva didapati $56,0 \%$ pada besaran kurva ringan $\left(20^{\circ}-29^{\circ}\right), 37,2 \%$ kurva sedang $\left(30^{\circ}-40^{\circ}\right)$, dan $36,7 \%$ kurva parah $\left(\geq 40^{\circ}\right)$.

Tabel 2. Gambaran Rata-rata In-brace Correction (IBC) terhadap Tipe Kurva dan Besaran Kurva

\begin{tabular}{|c|c|c|c|}
\hline \multirow[b]{2}{*}{ Variabel } & \multirow{2}{*}{$\begin{array}{c}\text { Mean } \\
\text { IBC } \\
(\%)\end{array}$} & \multicolumn{2}{|c|}{$95 \%$ CI } \\
\hline & & $\begin{array}{l}\text { Lower } \\
\text { Bound }\end{array}$ & $\begin{array}{l}\text { Upper } \\
\text { Bound }\end{array}$ \\
\hline \multicolumn{4}{|l|}{ Tipe Kurva } \\
\hline Kurva $S, L>T$ & 50,3 & 44,1 & 56,6 \\
\hline Kurva $S, T>L$ & 39,1 & 31,5 & 46,7 \\
\hline $\begin{array}{c}\text { Kurva T } \\
\text { Tunggal } \\
\text { Besaran Kurva }\end{array}$ & 40,3 & 35,0 & 45,7 \\
\hline Ringan (20-29) & 56,0 & 48,0 & 63,9 \\
\hline Sedang (30-40) & 37,2 & 31,9 & 42,5 \\
\hline Parah $(\geq 40)$ & 36,7 & 30,8 & 42,5 \\
\hline
\end{tabular}

Tabel 3. Hasil Analisis Two Way ANOVA Uji Besaran Kurva, Tipe Kurva, dan Interaksi Besaran Kurva dan Besaran Kurva terhadap In-Brace Correction (IBC)

\begin{tabular}{lcc}
\hline \multicolumn{1}{c}{ Variabel } & F hitung & P Value \\
\hline Besaran Kurva & 9.046 & 0,000 \\
Tipe Kurva & 3.668 & 0,029 \\
$\begin{array}{l}\text { Interaksi Besaran } \\
\text { Kurva dan Tipe }\end{array}$ & 0.430 & 0,787 \\
Kurva & & \\
\hline
\end{tabular}

Hasil analisis two way ANOVA pada Tabel.3 menunjukan bawha terdapat perbedaan yang signifikan IBC bedasarkan Besaran Kurva dan Tipe 
Kurva pada pasien adolescent idiopatik skoliosis dengan $p$-value adalah 0,000 dan 0,029 secara berurutan. Sedangkan, tidak ada interaksi Besaran Kurva dan Tipe Kurva signifikan terhadap IBC dengan $p$ value 0,787

\section{Pembahasan}

Besaran kurva pada saat penanganan awal skoliosis brace akan meningkatkan progresifitas kurva dengan cepat pada pasien yang memiliki tulang yang belum matang (S. Weinstein, 1997; S L Weinstein, Dolan, Cheng, Danielsson, \& Morcuende, 2008). Penggunaan brace dipercaya tidak efektif untuk dapat mencegah progresifitas bagi pasien AIS yang memiliki ketidakmatangan tulang dengan besaran kurva besar $\left(>40^{\circ}\right.$ ) (Hawary et al., 2019; Richards, Bernstein, D'Amato, \& Thompson, 2005). Dalam penelitian ini, terdapat perbedaan rata-rata IBC yang bermakna bedasarkan besaran kurva dengan $P=0,000$. Koreksi tertinggi terdapat pada kelompok pasien yang memiliki besaran kurva ringan $\left(20^{\circ}-29^{\circ}\right)$ dengan rata-rata $56,0 \%$. Dilanjutkan dengan besaran kurva sedang $\left(30^{\circ}-40^{\circ}\right)$ dan berat $\left(>40^{\circ}\right)$ dengan rata-rata IBC $37,2 \%$ dan $36,7 \%$ secara berturut-turut. Hal ini sesuai dengan penelitian yang dilakukan oleh (Lang et al., 2019) yang menyebutkan bahwa besaran cobb angle secara signifikan mempengaruhi hasil IBC.

Penelitian ini menunjukan bahwa semakin besar besaran kurva, semakin kecil IBC yang dihasilkan. Besarnya derajat kurva skoliosis menjadikan kurva menjadi kurang fleksibel untuk koreksi dengan brace (Ameri, Behtash, Mobini, \& Daraie, 2015). Rata-rata IBC pada kurva $>40$ derajat sebesar 36,7\% dengan IBC pada kurva ganda $\mathrm{L}>\mathrm{T}$ 41.9\%, kurva ganda $\mathrm{T}>\mathrm{L} 31,9 \%$, dan Kurva $\mathrm{T}$ tunggal $36.1 \%$. Dalam penelitian (Katz \& Durrani, 2001; Landauer et al., 2003) disebutkan bahwa pasien dengan cobb angle $>35^{\circ}$ dengan tipe kurva ganda, jika memiliki IBC $25 \%$ dan penggunaan brace selama minimal 18 jam, dapat meningkatkan kesuksesan dalam penganan AIS dengan bracing. Penelitian ini menunjukan bahwa IBC yang dihasilkan oleh klinik skoliosis dapat menunjang ke efektifan dari pengunaan brace pada pasien AIS jika penggunaan brace dengan patuh minimal 18 jam per hari sampai dengan tulang mencapai maturitas.
Penelitian ini menunjukan bahwa adanya perbedaan yang bermakna antara tipe kurva skoliosis dengan hasil IBC Pada Pasien AIS. Standar IBC yang perlu dicapai oleh brace sebesar $50 \%$ dari besar kurva awal (Knott et al., 2013). Tetapi berbeda hasil yang didapatkan (Katz \& Durrani, 2001), yang menyatakan IBC bisa dicapai baik tergantung tipe kurva yang dimiliki. Dalam penelitiannya disimpulkan batas minimum IBC bedasarkan tipe kurva. Untuk IBC kurva tunggal Thoracic adalah 40\%, kurva ganda thoracic > lumbar adalah $30 \%$, dan kurva ganda lumbar > thoracic 30\% untuk mencapai ke efektifan brace yang dinilai dengan progressifitas kurva $\leq 5^{\circ}$ saat tulang mencapai maturitas yang ditandai dengan risser 4 atau 5 atau tidak melibihi $45^{\circ}$ (Richards et al., 2005).

Dalam penelitian ini, prosentase hasil IBC yang dicapai adalah 50,3\% untuk kurva ganda lumbar > thoracic, 39,1\% untuk kurva kurva ganda thoracic > lumbar, dan 40,3\% untuk kurva tunggal Thoracic. Dapat disumpulkan, hasil IBC yang dicapai sudah baik melampaui batas minimum IBC. Tingginya tingkat IBC pada kurva lumbar, sejalan dengan penelitian oleh (Zaina, Donzelli, Lusini, \& Negrini, 2012) (Zaina, de Mauroy, Donzelli, \& Negrini, 2015) yang menyatakan IBC yang didaptkan pada lumbar lebih besar dibandingkan thoracolumbar dan thorak tunggal. Hal ini sesuai dengan anatomi tulang belakang tubuh manusia bahwa daerah lumbal lebih fleksibel jika dibandingkan dengan daerah tulang belakang yang lainnya khususnya daerah thoraks yang lebih terbatas pergerakan sendinya dikarenakan tersambung dengan tulang rusuk (Kuroki et al., 2015; Thompson, Hubbard, Jo, Virostek, \& Karol, 2017).

\section{Kesimpulan dan Saran}

Tipe kurva dengan IBC tertinggi secara berurutan yaitu tipe kurva ganda $\mathrm{L}>\mathrm{T}$, thoracic tunggal, dan kurva ganda $\mathrm{T}>\mathrm{L}$. IBC tertinggi bedasarkan besaran kurva yaitu dengan ringan , sedang, dan parah. Penelitian ini menyimpulkan bahwa tipe kurva dan besaran kurva yang diukur melaluk metode cobb angle merupakan faktor yang dapat mempengaruhi hasil in-brace correction (IBC). 
Dalam penelitian ini variabel yang diujikan terbatas pada besaran kurva dan tipe kurva. Variabel lain yang mempengaruhi IBC tidak tercantum pada data sekunder sehingga tidak dapat diujikan. Saran untuk penelitian selanjutnya yaitu dengan melakukan penelitian dengan metode cohort. Sehingga variabel faktor lain yang dapat mempengaruhi IBC dapat diujikan seperti indeks masa tubuh, tipe brace dan derajat rotasi serta peneliti selanjutnya dapat mengevaluasi perkembangan responden sampai akhir penanganan dengan bracing.

\section{Daftar Pustaka}

Ameri, E., Behtash, H., Mobini, B., \& Daraie, A. (2015). Predictors of curve flexibility in adolescent idiopathic scoliosis: A retrospective study of 100 patients. Acta Medica Iranica.

Brian V., R., \& Joseph B., S. (2001). Adolescent idiopathic scoliosis: review and current concepts. American Family Physician.

Clin, J., Aubin, C. É., Sangole, A., Labelle, H., \& Parent, S. (2010). Correlation between immediate in-brace correction and biomechanical effectiveness of brace treatment in adolescent idiopathic scoliosis. Spine.

https://doi.org/10.1097/BRS.0b013e3181cb46 f6

Hawary, R. El, Zaaroor-Regev, D., Floman, Y., Lonner, B. S., Alkhalife, Y. I., \& Betz, R. R. (2019). Brace treatment in adolescent idiopathic scoliosis: risk factors for failure-a literature review. Spine Journal. https://doi.org/10.1016/j.spinee.2019.07.008

Katz, D. E., \& Durrani, A. A. (2001). Factors that influence outcome in bracing large curves in patients with adolescent idiopathic scoliosis. Spine. https://doi.org/10.1097/00007632200111010-00012

(C) Poltekkes Kemenkes Jakarta I

Jl. Wijaya Kusuma No. 47-48 Cilandak Jakarta Selatan, Indonesia email: jurnalquality@poltekkesjakarta1.ac.id
Knott, P., Techy, F., Cotter, T., Jansen, L., Kove, P., Loving, J., ... Mardjetlko, S. (2013). Retrospective analysis of immediate in-brace correction of scoliosis attainable in patients with AIS: a SOSORT initiative. Scoliosis. https://doi.org/10.1186/1748-7161-8-s1-o49

Konieczny, M. R., Senyurt, H., \& Krauspe, R. (2013). Epidemiology of adolescent idiopathic scoliosis. Journal of Children's Orthopaedics. https://doi.org/10.1007/s11832-012-0457-4

Kuroki, H. (2018). Brace Treatment for Adolescent Idiopathic Scoliosis. Journal of Clinical Medicine, 7(6). https://doi.org/10.3390/jcm7060136

Kuroki, H., Inomata, N., Hamanaka, H., Higa, K., Chosa, E., \& Tajima, N. (2015). Predictive factors of Osaka Medical College (OMC) brace treatment in patients with adolescent idiopathic scoliosis. Scoliosis. https://doi.org/10.1186/s13013-015-0038-7

Landauer, F., Wimmer, C., \& Behensky, H. (2003). Estimating the final outcome of brace treatment for idiopathic thoracic scoliosis at 6month follow-up. Pediatric Rehabilitation. https://doi.org/10.1080/136384903100016368 17

Lang, C., Huang, Z., Sui, W., Di, M., He, S., Fan, H., ... Yang, J. (2019). Factors That Influence In-Brace Correction in Patients with Adolescent Idiopathic Scoliosis. World Neurosurgery, 123, e597-e603. https://doi.org/https://doi.org/10.1016/j.wneu. 2018.11.228

Maruyama, T., Grivas, T. B., \& Kaspiris, A. (2011). Effectiveness and outcomes of brace treatment: A systematic review. Physiotherapy Theory and Practice. https://doi.org/10.3109/09593985.2010.50398 9

Negrini, S., Donzelli, S., Aulisa, A. G., Czaprowski, ISSN 2655-2434

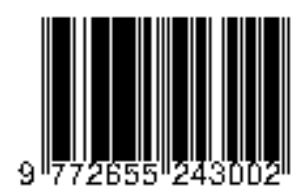


D., Schreiber, S., de Mauroy, J. C., ... Zaina, F. (2018). 2016 SOSORT guidelines: Orthopaedic and rehabilitation treatment of idiopathic scoliosis during growth. Scoliosis and Spinal Disorders. https://doi.org/10.1186/s13013-017-0145-8

Richards, B. S., Bernstein, R. M., D’Amato, C. R., \& Thompson, G. H. (2005). Standardization of criteria for adolescent idiopathic scoliosis brace studies: SRS Committee on Bracing and Nonoperative Management. Spine. https://doi.org/10.1097/01.brs.0000178819.90 239.d0

Thompson, R. M., Hubbard, E. W., Jo, C. H., Virostek, D., \& Karol, L. A. (2017). Brace success is related to curve type in patients with adolescent idiopathic scoliosis. Journal of Bone and Joint Surgery - American Volume. https://doi.org/10.2106/JBJS.16.01050

Weinstein, S. (1997). Point of View: The Natural History of Idiopathic Scoliosis: Incidence of Treatment in 15 Cohorts of Children Born Between 1963 and 1977. Spine. https://doi.org/10.1097/00007632199704010-00013

Weinstein, S L, Dolan, L. A., Cheng, J. C., Danielsson, A., \& Morcuende, J. A. (2008). Adolescent idiopathic scoliosis. Lancet, 371(9623), 1527-37 OD-2008/05/06. https://doi.org/10.1016/s0140-

6736(08)60658-3

Weinstein, Stuart L., Dolan, L. A., Wright, J. G., \& Dobbs, M. B. (2013). Effects of bracing in adolescents with idiopathic scoliosis. New England Journal of Medicine. https://doi.org/10.1056/NEJMoa1307337

Zaina, F., de Mauroy, J. C., Donzelli, S., \& Negrini, S. (2015). SOSORT Award Winner 2015: A

(C) Poltekkes Kemenkes Jakarta I

Jl. Wijaya Kusuma No. 47-48 Cilandak Jakarta Selatan, Indonesia email: jurnalquality@poltekkesjakarta1.ac.id multicentre study comparing the SPoRT and ART braces effectiveness according to the SOSORT-SRS recommendations. Scoliosis. https://doi.org/10.1186/s13013-015-0049-4

Zaina, F., Donzelli, S., Lusini, M., \& Negrini, S. (2012). Correlation between in-brace radiographic correction and short time brace results. Studies in Health Technology and Informatics. $\quad$ https://doi.org/10.3233/978-161499-067-3-342 